\title{
Relation between number of siblings and adult mortality and stroke risk: 25 year follow up of men in the Collaborative study
}

\author{
C L Hart, G Davey Smith
}

J Epidemiol Community Health 2003;57:385-391

See end of article for authors' affiliations

.....................

Correspondence to:

Dr C L Hart, Department of

Public Health, University of

Glasgow, 1 Lilybank

Gardens, Glasgow

G12 8RZ, UK;

c.l.harł@udcf.gla.ac.uk

Accepted for publication 2 August 2002

\begin{abstract}
Study objective: To investigate the relation between number of siblings, mortality risk, and stroke risk. Design: Prospective cohort study.

Setting: 27 workplaces in Scotland.

Participants: 5765 employed men aged 35-64 from a variety of different workplaces, screened between 1970 and 1973.

Main results: There were strong relationships between number of siblings and socioeconomic variables and also with adult behavioural measures. Men with greater numbers of siblings had an increased risk of dying of all causes, coronary heart disease, lung cancer, stomach cancer, and respiratory disease over a 25 year follow up period. Adjustment for risk factors could explain these associations, excepting stomach cancer mortality. With the definition of stroke as either a hospital admission for stroke or death from stroke, there was a strong relation between number of siblings and haemorrhagic stroke, but not ischaemic stroke.

Conclusions: Number of siblings is strongly related to mortality risk, but as it is also related to many risk factors, adjustment for these can generally explain the relation with mortality. The exceptions are stomach cancer mortality and haemorrhagic stroke, which are known to be related to deprivation in childhood, and, in the case of stomach cancer to childhood infection.
\end{abstract}

t t was reported a century ago that people from small families live longer than people from large families. ${ }^{1}$ However, number of siblings has not generally been analysed in large epidemiological studies, although it can be considered an indicator of material resources in the childhood home. People who have more siblings will, on average, have grown up in more overcrowded accommodation, with greater exposures to early infections, and with access to a less adequate diet. ${ }^{2}$ These factors could contribute to health in adulthood either through influencing childhood health (which in turn influences adult health), through an influence on the establishment of behavioural patterns in childhood, or through the latent effects of factors influenced by family size, such as chronic Helicobacter pylori infection or poorer infant and childhood nutrition, on adult disease risk. ${ }^{3}$ We have investigated the effect of number of siblings on adult health and mortality using a large cohort study that recorded number of siblings, in addition to several other socioeconomic variables and health measures, and that has 25 years of mortality follow up.

\section{METHODS}

This analysis was based on part of a cohort of employed people from 27 workplaces in Glasgow, Clydebank, and Grangemouth, who were screened between 1970 and 1973. The full sample consisted of 6022 men and 1006 women. Participants completed a questionnaire and attended a physical examination. Women have been excluded from this study because of their small numbers and because they were not representative of the socioeconomic spectrum, as most were from only two workplaces. Full details have been described elsewhere. ${ }^{4}$

The physical examination included measurement of blood pressure, height, weight, plasma total cholesterol, forced vital capacity (FVC), forced expiratory volume in one second $\left(\mathrm{FEV}_{1}\right)$, and a six lead electrocardiogram (ECG). The questionnaire collected information about smoking, alcohol consumption, angina from the Rose questionnaire, ${ }^{5}$ bronchitis, age leaving full time education, number of siblings, regular car driving, home address, main occupation of the participant's father, and the participant's own occupation.

Blood pressure was measured with the subject seated, and diastolic pressure was recorded at the disappearance of the fifth Korotkoff sound. Adjusted FVC was defined as the actual FVC as a percentage of the expected FVC. This was derived from a linear regression of age and height from a healthy subset $(n=841)$ of the study population who had never smoked and did not report suffering from phlegm, breathlessness, wheezy or whistling chest or weather affecting breathing. The derived regression equation was

$$
\begin{aligned}
& \text { Expected FVC }=-4.5736+(0.0586 \times \text { height })-(0.028 \\
& \times \text { age })
\end{aligned}
$$

where height was in centimetres and age was the age at screening in years.

The adjusted $\mathrm{FEV}_{1}$ was similarly defined as the actual $\mathrm{FEV}_{1}$ as a percentage of the expected $\mathrm{FEV}_{1} \cdot{ }^{4} \mathrm{~A}$ six lead ECG was made with the subject seated. The ECG was coded according to the Minnesota system with any of codes 1.1-1.3, 4.1-4.4, 5.15.3, and 7.1 being considered as evidence of ischaemia, encompassing diagnoses of definite myocardial infarction, myocardial ischaemia, and left bundle branch block. ${ }^{67}$ Angina was defined as definite grades I and II from the Rose Angina Questionnaire. ${ }^{8}$ Bronchitis was defined as having persistent and infective phlegm and being breathless. ${ }^{4}{ }^{9}$ Body mass index in $\mathrm{kg} / \mathrm{m}^{2}$ was calculated from the weight and height. Obesity was defined as having a body mass index of $30 \mathrm{~kg} / \mathrm{m}^{2}$ or above. A blood sample was taken for the measurement of whole plasma cholesterol. Units of alcohol consumed per week were calculated from responses to the questionnaire about usual weekly consumption of beer, spirits and wine. ${ }^{10}$

The home address at the time of screening was retrospectively postcoded, enabling deprivation category as defined by 


\begin{tabular}{|c|c|c|c|c|c|c|}
\hline & \multicolumn{5}{|c|}{ Siblings } & \multirow[b]{2}{*}{$p$ trend* } \\
\hline & 0 & $1-2$ & $3-4$ & $5-6$ & $7+$ & \\
\hline Number of men & 489 & 2043 & 1535 & 915 & 783 & \\
\hline Age† (y) & 46.4 & 47.1 & 48.6 & 49.7 & 49.9 & 0.0001 \\
\hline$\%$ adult social class I and II & 48.6 & 45.6 & 28.2 & 17.7 & 12.3 & 0.0001 \\
\hline$\%$ childhood social class I and II & 19.9 & 21.3 & 10.1 & 7.2 & 6.5 & 0.0001 \\
\hline$\%$ upwardly socially mobile & 58.2 & 58.4 & 52.0 & 49.2 & 48.3 & 0.0001 \\
\hline$\%$ downwardly socially mobile & 14.1 & 13.3 & 16.4 & 20.7 & 20.7 & 0.0001 \\
\hline$\%$ regular car drivers & 63.8 & 59.6 & 48.7 & 43.7 & 39.3 & 0.0001 \\
\hline$\%$ deprivation category 5-7 & 33.6 & 37.9 & 52.9 & 62.0 & 61.5 & 0.0001 \\
\hline$\%$ left education $\leqslant 14$ years & 30.0 & 35.1 & 57.3 & 66.4 & 74.3 & 0.0001 \\
\hline$\%$ angina & 4.4 & 5.4 & 7.0 & 6.5 & 7.0 & 0.09 \\
\hline$\%$ ECG ischaemia & 6.0 & 5.5 & 6.0 & 6.2 & 4.3 & 0.45 \\
\hline$\%$ MRC bronchitis & 0.9 & 1.1 & 2.7 & 3.3 & 3.4 & 0.0001 \\
\hline Height $(\mathrm{cm})$ & 174.2 & 174.0 & 172.7 & 171.5 & 170.7 & 0.0001 \\
\hline Body mass index $\left(\mathrm{kg} / \mathrm{m}^{2}\right)$ & 25.18 & 25.11 & 25.15 & 25.24 & 25.26 & 0.28 \\
\hline$\%$ obese $\left(\mathrm{BMI} \geqslant 30 \mathrm{~kg} / \mathrm{m}^{2}\right)$ & 7.6 & 5.5 & 5.1 & 6.7 & 8.1 & 0.12 \\
\hline Adjusted FEV $(\%)$ & 96.5 & 96.2 & 94.5 & 91.6 & 90.5 & 0.0001 \\
\hline Adjusted FVC (\%) & 97.8 & 98.0 & 97.1 & 95.4 & 94.3 & 0.0001 \\
\hline Cholesterol (mmol/l) & 6.0 & 5.99 & 5.85 & 5.78 & 5.73 & 0.0001 \\
\hline Systolic blood pressure $(\mathrm{mm} \mathrm{Hg})$ & 133.6 & 133.6 & 133.6 & 134.8 & 134.8 & 0.030 \\
\hline Diastolic blood pressure (mm Hg) & 83.7 & 83.8 & 83.6 & 84.2 & 84.3 & 0.14 \\
\hline$\%$ never smoked & 19.8 & 20.3 & 16.4 & 14.0 & 14.1 & 0.0001 \\
\hline$\%$ current cigarette smoker & 52.4 & 49.6 & 57.0 & 62.0 & 64.2 & 0.0001 \\
\hline Age started smoking (current) (y) & 19.1 & 18.7 & 17.8 & 17.5 & 17.6 & 0.0001 \\
\hline Age started smoking (ex) (y) & 18.3 & 18.0 & 17.7 & 17.1 & 17.8 & 0.028 \\
\hline Alcohol consumed per week (units) & 9.5 & 9.6 & 13.1 & 14.1 & 15.3 & 0.0001 \\
\hline
\end{tabular}

Carstairs and Morris to be ascertained..$^{11}$ This measure is an area based measure of deprivation, obtained from four census variables, male unemployment, overcrowding, car ownership, and the proportion of heads of households in social classes IV and V. A deprivation score for each postcode sector is obtained, which is converted to seven categories ranging from 1 (least deprived) to 7 (most deprived).

The questionnaire asked for the main occupation of the participant's father and the occupation at the time of screening. Social class was coded according to the contemporary Registrar General's Classification ${ }^{12}$ for each occupation. Upward social mobility was defined as moving upwards from father's to own adulthood social class. Downward social mobility was defined similarly.

Number of siblings were derived from answers to the two questions "How many brothers were there in your family?
(Excluding yourself)" and "How many sisters were there in your family? (Excluding yourself)". The answers to these questions were combined to form the number of siblings for each participant.

The analysis was based on 5765 men aged between 35 and 64 years at screening, who had not embarked from Britain during the follow up period.

Study participants were flagged at the National Health Service Central Register in Edinburgh. Dates of death up to the end of 1998 and their cause were provided. Causes of death were defined as coronary heart disease (CHD) (ICD9 codes 410-414 and 429.2), stroke (ICD9 430-438), lung cancer (ICD9 162), other smoking related cancer (ICD9 140, 141, $143-149,150,157,160,161,163,188$ and 189), stomach cancer (ICD9 151), other cancer (remainder of ICD9 codes

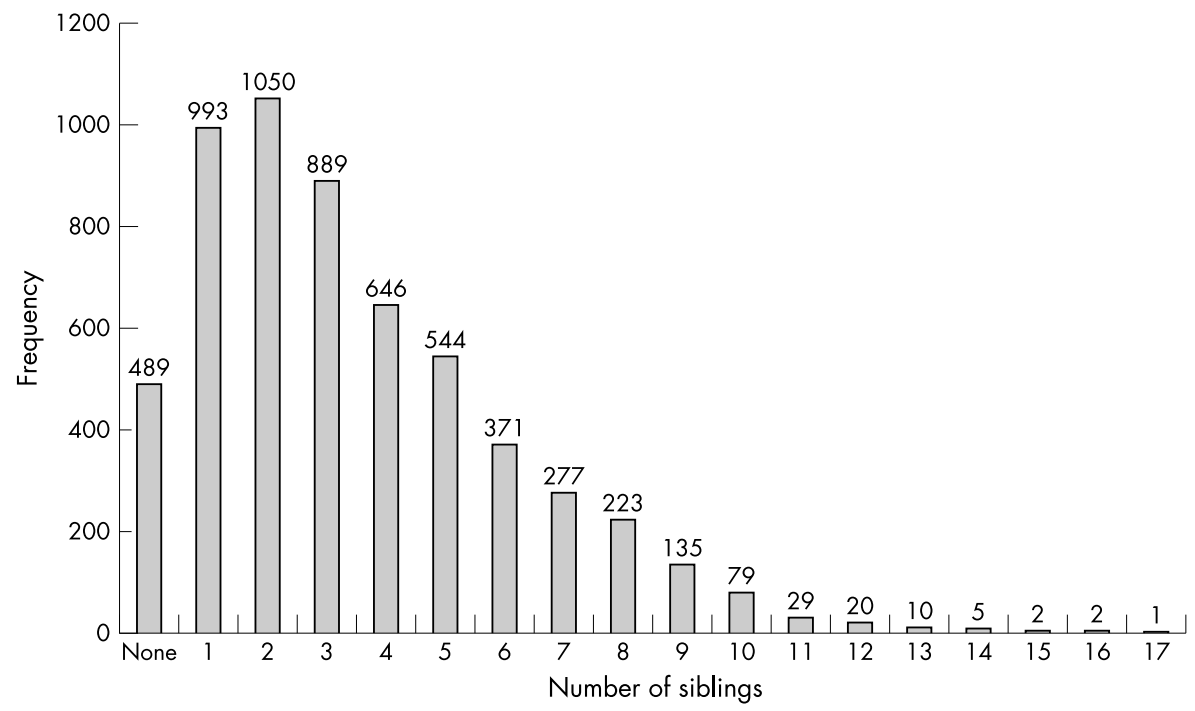

Figure 1 Number of siblings reported by men in the Collaborative study. 
Table 2 Regression coefficients or odds ratios and 95\% confidence intervals of baseline characteristics per sibling adjusted for age and socioeconomic variables

\begin{tabular}{|c|c|c|c|c|}
\hline & \multicolumn{4}{|l|}{ Adjusted for } \\
\hline & Age & $\begin{array}{l}\text { Age and adult } \\
\text { socioeconomic } \\
\text { measures* }\end{array}$ & $\begin{array}{l}\text { Age and childhood } \\
\text { socioeconomic } \\
\text { measurest }\end{array}$ & $\begin{array}{l}\text { Age and all } \\
\text { socioeconomic } \\
\text { measures* } \dagger\end{array}$ \\
\hline$\%$ angina & 1.04 (0.99 to 1.08 ) & $1.01(0.97$ to 1.05$)$ & $1.01(0.97$ to 1.05$)$ & $1.00(0.96$ to 1.05$)$ \\
\hline$\%$ ECG ischaemia & $0.98(0.94$ to 1.03$)$ & 0.97 (0.93 to 1.02 ) & $0.98(0.93$ to 1.02$)$ & 0.97 (0.93 to 1.02 ) \\
\hline$\%$ MRC bronchitis & 1.17 (1.11 to 1.24 ) & $1.11(1.04$ to 1.18$)$ & $1.11(1.05$ to 1.19$)$ & 1.09 (1.03 to 1.17$)$ \\
\hline Height $(\mathrm{cm})$ & $-0.49(-0.56$ to -0.42$)$ & $-0.21(-0.28$ to -0.14$)$ & $-0.27(-0.34$ to -0.20$)$ & $-0.17(-0.24$ to -0.10$)$ \\
\hline Body mass index $\left(\mathrm{kg} / \mathrm{m}^{2}\right)$ & $0.02(-0.01$ to 0.05$)$ & $0.02(-0.02$ to 0.05$)$ & $-0.0006(-0.03$ to 0.03$)$ & $0.008 \quad(-0.03$ to 0.04$)$ \\
\hline$\%$ obese $\left(B M I \geqslant 30 \mathrm{~kg} / \mathrm{m}^{2}\right)$ & 1.03 (0.99 to 1.08 ) & 1.01 (0.96 to 1.05 ) & $1.01(0.97$ to 1.06$)$ & $1.00(0.96$ to 1.05$)$ \\
\hline Adjusted FEV $(\%)$ & $-0.83(-1.03$ to -0.63$)$ & $-0.32(-0.53$ to -0.11$)$ & $-0.44(-0.65$ to -0.23$)$ & $-0.27(-0.48$ to -0.05$)$ \\
\hline Adjusted FVC (\%) & $-0.49(-0.64$ to -0.34$)$ & $-0.20 \quad(-0.35$ to -0.04$)$ & $-0.26(-0.41$ to -0.10$)$ & $-0.16(-0.32$ to -0.004$)$ \\
\hline Cholesterol (mmol/l) & $-0.04(-0.05$ to -0.03$)$ & $-0.009(-0.02$ to 0.002$)$ & $-0.02(-0.03$ to -0.01$)$ & $-0.006(-0.02$ to 0.01$)$ \\
\hline Systolic blood pressure (mm Hg) & $0.19(0.02$ to 0.37$)$ & $-0.10(-0.29$ to 0.08$)$ & $0.02(-0.17$ to 0.20$)$ & $-0.11(-0.29$ to 0.08$)$ \\
\hline Diastolic blood pressure $(\mathrm{mm} \mathrm{Hg}$ ) & $0.08(-0.03$ to 0.18$)$ & $-0.03(-0.14$ to 0.08$)$ & $-0.009(-0.12$ to 0.10$)$ & $-0.04(-0.16$ to 0.07$)$ \\
\hline$\%$ never smoked & 0.94 (0.91 to 0.96$)$ & $0.96(0.93$ to 0.99$)$ & $0.95(0.92$ to 0.98$)$ & 0.96 (0.93 to 0.99$)$ \\
\hline$\%$ current cigarette smoker & $1.09(1.06$ to 1.11$)$ & 1.03 (1.01 to 1.06 ) & 1.06 (1.03 to 1.08$)$ & 1.03 (1.01 to 1.06$)$ \\
\hline Age started smoking (current) (y) & $-0.16(-0.22$ to -0.11$)$ & $-0.08(-0.14$ to -0.02$)$ & $-0.07(-0.13$ to -0.01$)$ & $-0.06(-0.12$ to 0.002$)$ \\
\hline Age started smoking (ex) (y) & $-0.09(-0.16$ to -0.01$)$ & $0.008(-0.07$ to 0.09$)$ & $0.02(-0.06$ to 0.10$)$ & $0.03(-0.05$ to 0.11$)$ \\
\hline Alcohol consumed per week (units) & $0.84(0.68$ to 1.00$)$ & $0.45(0.29$ to 0.62$)$ & $0.69(0.52$ to 0.85$)$ & $0.48 \quad(0.32$ to 0.65$)$ \\
\hline
\end{tabular}

140-208), respiratory disease (ICD9 460-519), and accidents and violent deaths (ICD9 800-998 and E800-E999).

In addition, a computerised linkage with acute hospital discharges in Scotland provided records of all main diagnoses of stroke between 1972 and $1998 .^{13}$ These data were obtained for a project on stroke mortality and morbidity. Stroke was defined as ICD8 or ICD9 codes $430-438$, and as ICD10 codes I60 - I69 and G45. Haemorrhagic stroke was defined as ICD8 codes 430 and 431, ICD9 codes 430-432 and ICD10 codes I60I62. Ischaemic stroke was defined as ICD8 codes 432-435 and 437, ICD9 codes 433-435 and ICD10 codes I63, I65, I66 and G45. We have previously shown that risk factor associations with stroke admissions are very similar to risk factor associations with stroke deaths. ${ }^{14}$

Five groupings were constructed from number of siblings: no siblings, 1-2, 3-4, 5-6, and 7 or more. Analyses used either these groupings or the actual number of siblings. Cox's models $^{15}$ were used to calculate proportional hazards regression coefficients for sibling groups. The exponentiated proportional hazards regression coefficients are referred to as relative rates. Adjustments were made for risk factors by including the variables in the models. Adjustment for smoking was entered as number of cigarettes smoked per day for current and ex-smokers, with an extra term for ex-smokers ( 1 if

Table 3 Age adjusted relative rates of mortality and $95 \%$ confidence intervals by number of siblings in 5765 men aged $35-64$ from the Collaborative study in 25 years of follow up

\begin{tabular}{|c|c|c|c|c|c|c|c|c|}
\hline & \multicolumn{6}{|c|}{ Siblings } & \multirow{2}{*}{$\begin{array}{l}\text { Relative rate per } \\
\text { sibling }\end{array}$} & \multirow[b]{2}{*}{ Trend $\dagger$} \\
\hline & 0 & & $1-2^{*}$ & $3-4$ & $5-6$ & $7+$ & & \\
\hline $\begin{array}{l}\text { No of men } \\
\text { All cause }\end{array}$ & 489 & & 2043 & 1535 & 915 & 783 & & \\
\hline No of deaths & 149 & & 719 & 646 & 446 & 390 & & \\
\hline Relative rate & 0.89 & $(0.75$ to 1.07$)$ & 1 & $1.12(1.00$ to 1.24$)$ & 1.24 (1.10 to 1.40$)$ & 1.30 (1.15 to 1.47$)$ & 1.04 (1.02 to 1.06$)$ & $p<0.0001$ \\
\hline \multicolumn{9}{|c|}{ 1 } \\
\hline No of deaths & 69 & & 251 & 246 & 190 & 136 & & \\
\hline $\begin{array}{l}\text { Relative rate } \\
\text { Stroke }\end{array}$ & 1.18 & \multicolumn{2}{|c|}{ (1) } & $1.22(1.03$ to 1.46$)$ & 1.52 (1.26 to 1.84 ) & 1.31 (1.06 to 1.61$)$ & $1.04(1.01$ to 1.06$)$ & $p=0.005$ \\
\hline No of deaths & 7 & & 63 & 55 & 40 & 31 & & \\
\hline Relative rate & 0.50 & (0.23 to 1.08$)$ & 1 & $1.00(0.69$ to 1.44$)$ & $1.13(0.76$ to 1.69$)$ & $1.06(0.69$ to 1.63$)$ & $1.03(0.98$ to 1.09$)$ & $p=0.20$ \\
\hline \multicolumn{9}{|l|}{ Lung cancer } \\
\hline No of deaths & 11 & & 83 & 73 & 43 & 56 & & \\
\hline Relative rate & 0.57 & $(0.30$ to 1.06$)$ & 1 & $1.11(0.81$ to 1.52$)$ & $1.06(0.73$ to 1.54$)$ & 1.65 (1.17 to 2.33$)$ & 1.08 (1.03 to 1.12$)$ & $p=0.0009$ \\
\hline \multicolumn{9}{|c|}{ Other smoking related cancer } \\
\hline No of deaths & 6 & & 36 & 33 & 23 & 18 & & \\
\hline Relative rate & 0.72 & $(0.30$ to 1.70$)$ & 1 & $1.16(0.72$ to 1.87$)$ & $1.32(0.78$ to 2.23$)$ & 1.25 (0.71 to 2.20$)$ & $1.04(0.98$ to 1.12$)$ & $p=0.20$ \\
\hline \multicolumn{9}{|c|}{ 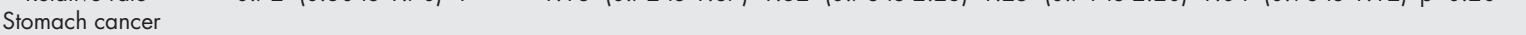 } \\
\hline No of deaths & 3 & & 13 & 21 & 11 & 16 & & \\
\hline \multirow{2}{*}{\multicolumn{9}{|c|}{ 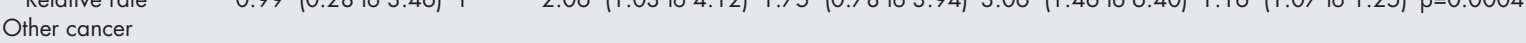 }} \\
\hline & & & & & & & & \\
\hline No of deaths & 20 & & 108 & 62 & 38 & 40 & & \\
\hline Relative rate & 0.80 & (0.49 to 1.28$)$ & 1 & $0.71(0.52$ to 0.98$)$ & 0.71 (0.49 to 1.03 ) & $0.90(0.62$ to 1.29$)$ & 0.99 (0.94 to 1.04$)$ & $p=0.68$ \\
\hline \multicolumn{9}{|c|}{ e. } \\
\hline No of deaths & 9 & & 52 & 47 & 38 & 35 & & \\
\hline \multicolumn{9}{|c|}{ 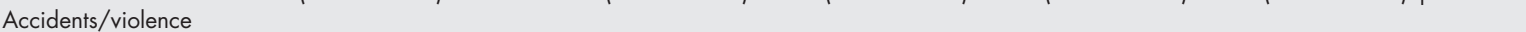 } \\
\hline No of deaths & 3 & & 19 & 24 & 10 & 8 & & \\
\hline Relative rate & 0.66 & $(0.20$ to 2.24$)$ & 1 & $1.67(0.91$ to 3.06$)$ & $1.16(0.53$ to 2.50$)$ & 1.11 (0.48 to 2.54$)$ & 1.02 (0.93 to 1.12 ) & $p=0.67$ \\
\hline
\end{tabular}


Table 4 Adjusted relative rates of mortality and $95 \%$ confidence intervals by number of siblings in 5765 men aged 35-64 from the Collaborative study in 25 years of follow up

\begin{tabular}{|c|c|c|c|c|c|c|c|c|c|c|c|}
\hline & \multicolumn{9}{|c|}{ Siblings } & \multirow{2}{*}{$\begin{array}{l}\text { Relative rate per } \\
\text { sibling }\end{array}$} & \multirow[b]{2}{*}{ Trend $\dagger$} \\
\hline & 0 & & $1-2 *$ & $3-4$ & & $5-6$ & & $7+$ & & & \\
\hline \multicolumn{12}{|l|}{ All cause } \\
\hline Relative rate $\neq$ & 0.84 & $(0.71$ to 1.01$)$ & 1 & 1.07 & $(0.96$ to 1.19$)$ & 1.17 & (1.04 to 1.32$)$ & 1.24 & (1.10 to 1.41$)$ & 1.04 (1.02 to 1.05$)$ & $p<0.0001$ \\
\hline Relative rate $\S$ & 0.91 & (0.76 to 1.09 ) & 1 & 1.01 & $(0.90$ to 1.12$)$ & 1.05 & (0.93 to 1.19 ) & 1.07 & (0.93 to 1.21$)$ & 1.01 (0.99 to 1.03 ) & $p=0.19$ \\
\hline Relative rate & 0.87 & $(0.73$ to 1.04$)$ & 1 & 0.98 & $(0.88$ to 1.10$)$ & 1.01 & $(0.89$ to 1.14$)$ & 1.03 & $(0.90$ to 1.18$)$ & $1.01(0.99$ to 1.02$)$ & $p=0.35$ \\
\hline \multicolumn{12}{|c|}{ של. } \\
\hline Relative rate $\ddagger$ & 1.13 & (0.86 to 1.47$)$ & 1 & 1.18 & $(0.99$ to 1.41$)$ & 1.45 & $(1.20$ to 1.76$)$ & 1.26 & (1.02 to 1.55$)$ & 1.03 (1.01 to 1.06$)$ & $p=0.013$ \\
\hline Relative rate§ & 1.21 & $(0.93$ to 1.58$)$ & 1 & 1.11 & $(0.92$ to 1.33$)$ & 1.29 & $(1.06$ to 1.57$)$ & 1.08 & $(0.86$ to 1.34$)$ & $1.01(0.98$ to 1.03$)$ & $p=0.66$ \\
\hline Relative rate & 1.20 & (0.92 to 1.57$)$ & 1 & 1.11 & $(0.92$ to 1.32$)$ & 1.28 & $(1.05$ to 1.56$)$ & 1.08 & $(0.87$ to 1.35$)$ & 1.01 (0.98 to 1.03$)$ & $p=0.58$ \\
\hline \multicolumn{12}{|c|}{ 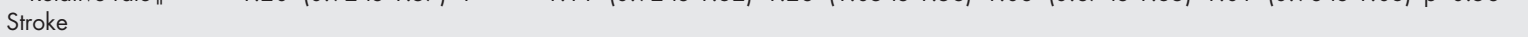 } \\
\hline Relative ratef & 0.45 & (0.21 to 0.99$)$ & 1 & 0.96 & $(0.67$ to 1.38$)$ & 1.07 & $(0.72$ to 1.60$)$ & 1.01 & $(0.65$ to 1.55$)$ & 1.03 (0.98 to 1.09 ) & $p=0.25$ \\
\hline Relative rate§ & 0.50 & $(0.23$ to 1.09$)$ & 1 & 0.93 & $(0.64$ to 1.35$)$ & 1.01 & $(0.67$ to 1.53$)$ & 0.90 & (0.57 to 1.42 ) & $1.01(0.96$ to 1.07$)$ & $p=0.64$ \\
\hline Relative rate & 0.45 & (0.20 to 0.98$)$ & 1 & 0.90 & $(0.62$ to 1.30$)$ & 0.99 & $(0.65$ to 1.50$)$ & 0.88 & (0.56 to 1.39 ) & 1.01 (0.96 to 1.07$)$ & $p=0.61$ \\
\hline \multicolumn{12}{|c|}{ (1) } \\
\hline Relative rate $\ddagger$ & 0.50 & $(0.27$ to 0.93$)$ & 1 & 1.02 & $(0.74$ to 1.40$)$ & 0.94 & $(0.65$ to 1.36$)$ & 1.51 & (1.07 to 2.12 ) & 1.07 (1.02 to 1.11$)$ & $p=0.003$ \\
\hline Relative rate§ & 0.58 & $(0.31$ to 1.10$)$ & 1 & 0.94 & $(0.68$ to 1.30$)$ & 0.82 & $(0.56$ to 1.20$)$ & 1.20 & $(0.83$ to 1.72$)$ & 1.03 (0.98 to 1.08$)$ & $p=0.20$ \\
\hline Relative rate & 0.51 & $(0.27$ to 0.96$)$ & 1 & 0.89 & (0.64 to 1.22$)$ & 0.74 & (0.51 to 1.09 ) & 1.11 & (0.77 to 1.60$)$ & 1.03 (0.98 to 1.07$)$ & $p=0.30$ \\
\hline \multicolumn{12}{|c|}{ Other smoking related cancer } \\
\hline Relative rate $\ddagger$ & 0.68 & $(0.29$ to 1.62$)$ & 1 & 1.13 & $(0.70$ to 1.81$)$ & 1.25 & $(0.74$ to 2.13$)$ & 1.20 & $(0.68$ to 2.12$)$ & $1.04(0.97$ to 1.11$)$ & $p=0.24$ \\
\hline Relative rate $\S$ & 0.73 & $(0.31$ to 1.74$)$ & 1 & 1.06 & $(0.65$ to 1.72$)$ & 1.13 & $(0.65$ to 1.95$)$ & 1.04 & $(0.57$ to 1.90$)$ & $1.02(0.95$ to 1.10$)$ & $p=0.64$ \\
\hline Relative rate & 0.69 & $(0.29$ to 1.65$)$ & 1 & 1.02 & $(0.63$ to 1.66$)$ & 1.09 & $(0.63$ to 1.89$)$ & 1.00 & $(0.54$ to 1.82$)$ & 1.01 (0.94 to 1.09$)$ & $p=0.71$ \\
\hline \multicolumn{12}{|c|}{ 然 } \\
\hline Relative rate $\neq$ & 0.94 & $(0.27$ to 3.29$)$ & 1 & 1.97 & $(0.98$ to 3.95$)$ & 1.65 & $(0.74$ to 3.72$)$ & 2.95 & (1.41 to 6.17 ) & 1.15 (1.06 to 1.25$)$ & $p=0.0006$ \\
\hline Relative rate§ & 0.98 & $(0.28$ to 3.45$)$ & 1 & 1.95 & $(0.96$ to 3.95$)$ & 1.63 & $(0.70$ to 3.77$)$ & 2.73 & (1.24 to 6.00$)$ & $1.14(1.05$ to 1.25$)$ & $p=0.003$ \\
\hline Relative rate & 0.94 & $(0.27$ to 3.29$)$ & 1 & 1.91 & $(0.94$ to 3.88$)$ & 1.53 & $(0.66$ to 3.54$)$ & 2.66 & (1.21 to 5.85$)$ & 1.14 (1.04 to 1.24$)$ & $p=0.003$ \\
\hline \multicolumn{12}{|c|}{ 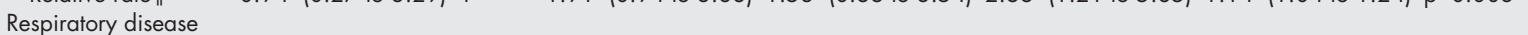 } \\
\hline Relative rate & 0.68 & (0.33 to 1.38$)$ & 1 & 1.01 & $(0.68$ to 1.50$)$ & 1.26 & (0.82 to 1.92$)$ & 1.42 & (0.92 to 2.19 ) & 1.05 (1.00 to 1.11$)$ & $p=0.07$ \\
\hline Relative rate§ & 0.78 & $(0.38$ to 1.58$)$ & 1 & 0.86 & (0.58 to 1.29 ) & 0.97 & $(0.63$ to 1.51$)$ & 1.01 & (0.64 to 1.59 ) & $1.00(0.94$ to 1.06$)$ & $p=0.97$ \\
\hline Relative rate & 0.72 & (0.35 to 1.47$)$ & 1 & 0.79 & $(0.52$ to 1.18$)$ & 0.83 & $(0.54$ to 1.30$)$ & 0.81 & (0.51 to 1.29 ) & $0.97(0.92$ to 1.03$)$ & $p=0.38$ \\
\hline
\end{tabular}

*Baseline category. †Using siblings as a continuous variable. ‡Adjusted for age and smoking. §Adjusted for age, social class, father's social class, car user, deprivation category, and education. IAdjusted for age, smoking, social class, father's social class, car user, deprivation category, education, user, deprivation category, and education. 'Adjusted for age, smoking, social class, fathe
bronchitis, height, adjusted $\mathrm{FEV}_{1}$, systolic blood pressure, cholesterol, and units of alcohol.

ex-smokers, 0 otherwise). Social class, father's social class, deprivation category, height, adjusted FEVl, systolic blood pressure, cholesterol, and units of alcohol were entered as continuous variables. Car user and bronchitis were added as discrete variables and education was entered as an ordinal variable representing four groups of age leaving full time education (12-14, 15-16, 17-18, and 19 or over). Cox's models were used to calculate tests for trend and the relative rate per sibling, using actual number of siblings as a continuous variable. Survival time was taken from the date of screening until the date of death or 25 years from the date of screening. For analyses of stroke mortality or events, survival time was taken from the date of screening until either the date of hospital admission for stroke, or the date of death from stroke if no hospital admission for stroke were found. Means of continous variables were standardised for age using PROC GLM in the SAS system, with tests for trend and regression coefficients being obtained by regression analysis. Proportions of categorical variables were age standardised by the direct method, using the study population as the standard, with tests for trend and odds ratios obtained by logistic regression.

\section{RESULTS}

Figure 1 shows the number of siblings reported. It was most common to have one or two siblings, although the largest number reported was 17 . Table 1 presents characteristics measured at baseline in terms of sibling groups. Men with more siblings were older at baseline. There were strong relations between number of siblings and the socioeconomic variables. Men with more siblings were less likely to be in social classes I and II, their fathers were also less likely to have been in social classes I and II, they were less likely to be regular car drivers, more likely to live in deprived areas, and to have left full time education at age 14 or below. Despite having more opportunity for upward social mobility, men with more siblings were less likely to be upwardly mobile. There were no meaningful associations of number of siblings with angina, ECG ischaemia or body mass index, weak positive associations with blood pressure, strong positive associations with bronchitis, and strong inverse associations with cholesterol and both lung function measures. There was an apparent $U$ shaped relation between number of siblings and obesity, although there was no statistical evidence of a quadratic trend $(p=0.51)$. There was a graded relation with height, with only children being the tallest on average. The percentage of men who had never smoked was inversely related to number of siblings. The percentage of current cigarette smokers and the amount of alcohol consumed were positively associated with number of siblings, although fewer of the men with one or two siblings smoked than only children. The age when smoking began for both current and former smokers was inversely related to number of siblings.

Table 2 presents for baseline characteristics, the regression coefficients for continuous variables and odds ratios for discrete variables per sibling adjusted for age and also adult (adult social class, deprivation category and regular car driver) and childhood (father's social class and age leaving full time education) socioeconomic measures. Compared with age adjusted results, additional adjustment for adult and childhood socioeconomic variables generally attenuated the relation between siblings and the risk factors at baseline. Lung function measures saw particularly large decreases and additional adjustment for smoking decreased the regression coefficients further to -0.23 (95\% confidence interval -0.44 to -0.01 ) for $\mathrm{FEV}_{1}$ and -0.14 (95\% confidence interval -0.30 to 0.02 ) for FVC. Additional adjustment for smoking did not change the odds ratios for bronchitis.

Mortality in 25 years of follow up was related to number of siblings (table 3). The group with 1-2 siblings was taken as the baseline. Men with seven or more siblings had a 30\% higher 
Table 5 Relative rates of haemorrhagic and ischaemic stroke and 95\% confidence intervals by number of siblings in 5765 men aged 35-64 from the Collaborative study in 25 years of follow up. Stroke defined as either stroke hospital admission or death

\begin{tabular}{|c|c|c|c|c|c|c|}
\hline & \multicolumn{4}{|c|}{ Siblings } & \multirow{2}{*}{$\begin{array}{l}\text { Relative rate per } \\
\text { sibling }\end{array}$} & \multirow[b]{2}{*}{ Trend $\dagger$} \\
\hline & $0-2 *$ & 3 or 4 & 5 or 6 & 7 or more & & \\
\hline Number of participants & 2532 & 1535 & 915 & 783 & & \\
\hline \multicolumn{7}{|l|}{ All stroke } \\
\hline Number of strokes & 161 & 105 & 77 & 73 & & \\
\hline Relative rate $\neq(95 \% \mathrm{Cl})$ & 1 & 0.99 (0.77 to 1.27$)$ & 1.17 (0.89 to 1.53$)$ & 1.34 (1.02 to 1.78 ) & 1.05 (1.01 to 1.09 ) & 0.010 \\
\hline Relative rate§ $(95 \%$ Cl) & 1 & 0.88 (0.68 to 1.13 ) & 0.97 (0.73 to 1.29 ) & 1.07 (0.80 to 1.44$)$ & 1.02 (0.98 to 1.06$)$ & 0.36 \\
\hline \multicolumn{7}{|l|}{ Haemorrhagic } \\
\hline Number of strokes & 14 & 14 & 9 & 10 & & \\
\hline Relative rateł $(95 \% \mathrm{Cl})$ & 1 & 1.63 (0.77 to 3.42$)$ & 1.74 (0.75 to 4.05$)$ & 2.33 (1.02 to 5.29 ) & 1.11 (1.01 to 1.23$)$ & 0.031 \\
\hline Relative rate§ $(95 \%$ CI) & 1 & 1.60 (0.74 to 3.45$)$ & 1.74 (0.71 to 4.24$)$ & 2.29 (0.95 to 5.53 ) & 1.11 (1.00 to 1.23 ) & 0.058 \\
\hline \multicolumn{7}{|l|}{ Ischaemic } \\
\hline Number of strokes & 43 & 23 & 16 & 18 & & \\
\hline Relative rateł $(95 \% \mathrm{Cl})$ & 1 & $0.86(0.52$ to 1.44$)$ & $1.00(0.56$ to 1.78$)$ & $1.36(0.78$ to 2.37$)$ & 1.03 (0.96 to 1.11$)$ & 0.45 \\
\hline Relative rate $\S(95 \% \mathrm{Cl})$ & 1 & $0.81 \quad(0.48$ to 1.37$)$ & 0.88 (0.48 to 1.61$)$ & 1.18 (0.66 to 2.14$)$ & 1.01 (0.93 to 1.09 ) & 0.81 \\
\hline
\end{tabular}

*Baseline category. †Using siblings as a continuous variable. $\ddagger$ Adjusted for age. §Adjusted for age, smoking, social class, father's social class, car user, deprivation category, education, bronchitis, height, adjusted FEV 1 , systolic blood pressure, cholesterol, and units of alcohol.

risk of dying than men with $1-2$ siblings. Similar results were seen for deaths from CHD. Only children had a lower risk of stroke mortality than men with any number of siblings. Men with seven or more siblings had the highest relative rate of lung cancer mortality, and only children had the lowest. Similar results were seen for mortality from other smoking related cancers. The strongest positive association between number of siblings and any examined cause of death was with stomach cancer, with a greater than threefold risk difference between men with seven or more siblings and men with 0-2 siblings. There was no clear relation with other non-smoking related cancers as a combined end point, nor with accidental and violent deaths. Respiratory disease deaths were strongly associated with number of siblings, with men in the highest group having a $50 \%$ higher risk than men with $1-2$ siblings.

Table 4 presents the relative rates of mortality adjusted for other risk factors. Adjustment for smoking could explain some of the relation between number of siblings and all cause, CHD, stroke, lung cancer, other smoking related cancer, stomach cancer, and respiratory disease mortality. Adjustment for socioeconomic variables ( social class, father's social class, car user, deprivation category, and education) attenuated the relationships between number of siblings and all the above causes of death. Adjustment for smoking, the socioeconomic variables, bronchitis, height, adjusted $\mathrm{FEV}_{1}$, systolic blood pressure, cholesterol and units of alcohol consumed further attenuated the relative rates. Number of siblings only remained substantially associated with stomach cancer mortality. Only children retained a lower risk of stroke and lung cancer mortality than all men with siblings, but there was no consistent gradient according to number of siblings. Rerunning the models in table 4 using only variables which were significant at the $\mathrm{p}<0.1$ level did not affect the results.

With the definition of stroke as either a hospital admission for stroke or a death from stroke, 416 men had a stroke in the follow up period (table 5). Of these, 47 were classified as haemorrhagic strokes and 100 as ischaemic. Because of the small numbers, the first two categories of siblings were combined to form a category of none to two siblings and this was used as the baseline. There was a strong positive trend with haemorrhagic stroke, but not with ischaemic stroke. Men with seven or more siblings were over twice as likely to have a haemorrhagic stroke than men with two or less siblings. Adjustment for other risk factors made little difference to the relative rates for haemorrhagic stroke, although the significance levels were lessened by adjustment. Adjusting only for risk factors significant at the $\mathrm{p}<0.1$ level did not affect the results. In a similar analysis of stroke subtype by father's social

\section{Key points}

- Number of siblings is related to adverse behavioural, socioeconomic, and health measures.

- There are strong relationships between number of siblings and risk of different causes of death, but with the exception of stomach cancer mortality, these relationships can be explained by the adverse risk factors.

- Number of siblings is related to haemorrhagic, but not ischaemic, stroke.

class, the age adjusted relative rate of haemorrhagic stroke was 2.84 (95\% confidence interval 1.12 to 7.20 ) for men with fathers in manual social classes compared with men with fathers in non-manual social classes. Adjustment for other risk factors and adult socioeconomic measures increased the relative rate to 3.22 ( 1.15 to 9.03 ). Similar results for ischaemic stroke were 1.25 ( 0.77 to 2.03 ) when adjusted for age and 0.92 (0.53 to 1.61) when fully adjusted.

\section{DISCUSSION}

We have shown that number of siblings was strongly associated with other socioeconomic variables, measures of health in adulthood, and mortality in 25 years of follow up. Adjustment for the other variables could account for many of the observed associations, although not with stomach cancer or haemorrhagic stroke. There are few mortality and adult health studies in the epidemiological literature using number of siblings, although some studies of birth order also include number of siblings. ${ }^{16}{ }^{17}$ A study of Swedish men and women found that having a large family (defined as having four or more brothers and/or sisters) was related to poorer health in adulthood. ${ }^{18}$ Other studies have found that patients with diabetes, peptic and duodenal ulcers, arthritis, contagious diseases, and increased sensitivity to physical pain are more likely to come from large families. ${ }^{19}$ Our study found a strong relationship between siblings and bronchitis in adulthood and also lung function which was attenuated after further adjustment for socioeconomic variables. Our findings provided weak evidence of higher blood pressure in men with over five siblings. Other studies have produced different results for blood pressure. An inverse relation with siblings was found in a study of British children aged between 5 and 7.5 years $^{20}$ and in male Glasgow University students. ${ }^{21}$ Higher blood pressure was found in adults without siblings compared with those with siblings in the Buffalo Blood Pressure Study. ${ }^{22}$ Obesity in 


\section{Policy implications}

Number of siblings is related to risk of childhood infection, which is known to be related to stomach cancer risk in adulthood through $\mathrm{H}$ pylori infection. The paper contributes to the growing body of evidence linking processes generating stomach cancer and haemorrhagic stroke risk within populations.

young men has been found to be greater in those with less siblings ${ }^{23}$ although we found a suggestion of a $\mathrm{U}$ shaped relation. Many studies have found number of siblings to be inversely related to height, in agreement with the current study. ${ }^{16} 24$ Achieved height in adulthood is related to early life social circumstances, nutrition and prenatal growth. ${ }^{26}$ For men born around the time of the present cohort, number of siblings was not related to birth weight, but was related to poorer post-natal growth. ${ }^{27}$

Of particular note were the strong relations between adult behavioural factors and siblings-as number of siblings increased, the amount of alcohol consumed per week increased and men were more likely be smokers and to have started smoking at a younger age. A risk factor acting in the opposite way was cholesterol-men with more siblings had lower (that is, healthier) cholesterol levels. In studies of this era, before health messages on reduction of fat consumption were common, higher cholesterol was seen in the more affluent groups.

Studies relating number of siblings to mortality are sparse. In a study of Swedish men and women, having a large family was associated with an increased although not statistically robust mortality risk. ${ }^{18}$ Conversely, in a study of intellectually gifted children in California begun in the 1920s, number of siblings was inversely associated with all cause mortality in women, and non-cardiovascular, non-cancer mortality in both men and women. ${ }^{17}$ However, this was a highly selected cohort and may not be generally representative. We found positive associations between number of siblings and all cause, CHD, stroke, lung cancer, other smoking related cancers, stomach cancer, and respiratory disease mortality. Adjusting for several risk factors could explain the associations with all of these causes of death, excepting stomach cancer. Adjusting for several socioeconomic variables could be over-adjustment, as siblings could "explain" or at least contribute to childhood socioeconomic effects.

CHD has been the most investigated cause of death in previous studies, which have found inconsistent results, and have generally not been able to adequately adjust for risk factors in adulthood. ${ }^{28-32}$ Our study found no robust association. For respiratory mortality the direction of association was reversed on adjustment for other risk factors. These included some factors that could be influenced by family size in childhood, however, including lung function and bronchitis. ${ }^{3}$ Although adjustment for socioeconomic position and smoking attenuated associations of sibling number with these measures, some relation remained. Thus chronic obstructive pulmonary disease and susceptibility to respiratory infections in adulthood could be influenced by family size through these pathways. Conversely, the number of siblings is protective against asthma, at least in children, ${ }^{33}$ and it is possible, therefore, that number of siblings may have opposite effects on different components of respiratory disease in adulthood.

Stomach cancer mortality was strongly associated with number of siblings. This could reflect Helicobacter pylori infection, which is known to be a risk factor for cancer of the body of the stomach, ${ }^{34}$ is generally acquired in childhood, ${ }^{35}$ and, in another Scottish survey, shows a strong graded association with number of siblings, similar in magnitude to the association we show with stomach cancer. ${ }^{36}$ Limited previous evidence links sibling number to stomach cancer risk, ${ }^{37}$ although a recent study of comparatively young Swedish adults failed to confirm this, ${ }^{38}$ perhaps because of the changing nature of stomach cancer in wealthy countries, where a substantial decline in overall stomach cancer mortality has been accompanied by a switch of the predominant component from cancer of the body of the stomach-which is related to Helicobacter pylori infection-to cancer of the gastric cardia, which is unrelated to Helicobacter pylori infection. ${ }^{34}$

There was only weak evidence of a graded association between number of siblings and stroke mortality, although men who were only children had about half the risk of men with any number of siblings. The findings for stroke (hospital admission or death) by subtype were of particular interest and confirmed previous findings of different relationships with haemorrhagic and ischaemic stroke. The strong relationships seen between siblings and haemorrhagic stroke, and between father's social class and haemorrhagic stroke are consistent with findings in another Scottish cohort study, the Renfrew/ Paisley general population study, in which there was a strong inverse relation between height and haemorrhagic stroke, each $10 \mathrm{~cm}$ increment in height resulting in a 30\% decrease in risk, but little association with ischaemic stroke. ${ }^{39}$ In a Finnish study, haemorrhagic stroke was inversely associated with birth weight adjusted for head circumference. ${ }^{40}$ The authors suggested that reduced fetal growth could increase the risk of haemorrhagic stroke by permanently changing the cerebral arterial structure. A recent study showed birth weight to be inversely associated with haemorrhagic stroke in Swedish men and women, which was strengthened when adjusting for birth length and head circumference. ${ }^{41}$ These authors suggested that the risk of haemorrhagic stroke was related to impaired growth of soft tissue mass relative to bone growth. It is possible that number of siblings is related to haemorrhagic stroke because it is associated with poorer fetal growth, however, the association between number of siblings and birth weight has not been well described. Indeed birth weight tends to increase with parity from the first birth on, although at high birth orders there is some evidence of a decline in birth weight. ${ }^{42}$ Short birth intervals, which will occur in families that end up with a high number of offspring, are associated with lower birth weight, however. ${ }^{42}$ Thus the exact prediction regarding how number of siblings would relate to birth weight is unclear. Furthermore, as CHD is also related to poor fetal growth, it would be expected that a similar association with CHD should be observed if fetal growth mediated the siblingstroke association.

We have previously reported on the influence of other socioeconomic variables and stroke risk (hospital admission or death) in the Collaborative study cohort. ${ }^{13}$ The most striking results were for father's social class-that is, socioeconomic circumstances in childhood-with men growing up in households with fathers in manual occupations having a $70 \%$ increased risk of having a stroke than men with fathers in non-manual occupations. Men who were upwardly socially mobile (had a father with a manual occupation and their own occupation in adulthood was non-manual) had the same risk of stroke as stable manual men (father manual and own occupation manual). This suggests the importance of early life conditions for stroke risk. Poor early life conditions as indexed by number of siblings in this study confirm this suggestion.

The association of number of siblings with two specific causes-stomach cancer and haemorrhagic stroke-after adjustment for childhood and adulthood socioeconomic circumstances and other risk factors suggests a link between these conditions. This link is supported by consideration of time trends in these conditions-which both decreased markedly in Britain during the 20th century ${ }^{43}$ and in an ecological analysis that found that the infant mortality rate in the 1920s was associated with stomach cancer and overall stroke mortality in the 1990s across 27 countries, suggesting that early life circumstances, particularly those that would 
influence infectious diseases in early childhood, are important in the aetiology of these conditions. ${ }^{44}$ The potential contribution of a childhood acquired infection in haemorrhagic stroke deserves further investigation. Current evidence suggests that Helicobacter pylori infection is not robustly associated with stroke, ${ }^{45}$ but there are no data specifically on haemorrhagic stroke, and most strokes in previous studies would have been ischaemic. The shared epidemiological patterns of stomach cancer and haemorrhagic stroke could be attributable to childhood infections contributing to both diseases, and declining family size may have contributed to the secular decreases across the 20th century.

Number of siblings is related to the cause of death, which a priori reasoning suggests it should be: stomach cancer, presumably through increased risk of Helicobacter pylori infection among those with more siblings. Furthermore, number of siblings is also strongly related to peptic ulcer risk in this cohort (C Metcalfe, personal communication, 2001). Therefore number of siblings seems to be serving as a marker of risk of at least some infections in childhood. The lack of association of number of siblings with CHD, ischaemic stroke, and other cancers suggests-within the limits of the power of this study-that childhood infections that would be indexed by number of siblings are not important contributors to the aetiology of these conditions.

\section{ACKNOWLEDGEMENTS}

Victor M Hawthorne, Charles R Gillis, and David J Hole were responsible for the original study of the cohort and Pauline L MacKinnon is responsible for updating mortality.

\section{Authors' affiliations}

C L Hart, Department of Public Health, University of Glasgow, Glasgow, UK

G Davey Smith, Department of Social Medicine, University of Bristol, Bristol, UK

Funding: the research received grants from Chest, Heart and Stroke Scotland, and the Stroke Association.

Conflicts of interest: none.

\section{REFERENCES}

1 Beeton $M$, Pearson K. On the inheritance of the duration of life and the intensity of natural selection in man. Biometrika 1901;1:50-89.

2 Blane D, Davey Smith G, Hart C. Some social and physical correlates of intergenerational social mobility: evidence from the West of Scotland Collaborative Study. Sociology 1999;33:169-83.

3 Davey Smith G, Gunnell D, Ben-Shlomo Y. Life-course approaches to socio-economic differentials in cause-specific adult mortality. In: Leon D, Walt $G$, eds. Poverty, inequality and health. Oxford: Oxford University Press, 2000:88-124.

4 Davey Smith G, Hart C, Hole D, et al. Education and occupational social class: which is the more important indicator of mortality risk? J Epidemiol Community Health 1998;52:153-60

5 Rose GA. The diagnosis of ischaemic heart pain and intermittent claudication in field surveys. Bull World Health Organ 1962;27:645-58.

6 Prineas RJ, Crow RS, Blackburn H. The Minnesota code manual of electrocardiographic findings: standards and procedures for measurement and classification. Boston, MA: John Wright, 1982.

7 Hawthorne VM, Watt GCM, Hart CL, et al. Cardiorespiratory disease in men and women in urban Scotland: baseline characteristics of the Renfrew/Paisley (Midspan) Study population. Scott Med J 1995;40:102-7

8 Hart CL, Watt GCM, Davey Smith G, et al. Pre-existing ischaemic heart disease and ischaemic heart disease mortality in women compared with men. Int J Epidemiol 1997;26:508-15.

9 Medical Research Council. Definition and classification of chronic bronchitis for epidemiological purposes. Lancet 1965;i:775-9.

10 Hart CL, Davey Smith G, Hole DJ, et al. Alcohol consumption and mortality from all causes, coronary heart disease and stroke: results from a prospective cohort study of Scottish men with 21 years of follow up. BM 1999;318:1725-9.

11 Carstairs V, Morris R. Deprivation and health in Scotland. Aberdeen: Aberdeen University Press, 1991
12 General Register Office. Classification of occupations 1966. London: HMSO, 1966

13 Hart CL, Hole DJ, Davey Smith G. Influence of socioeconomic circumstances in early and later life on stroke risk among men in a Scottish cohort study. Stroke 2000;31:2093-7.

14 Hart C, Hole D, Davey Smith G. Comparison of risk factors for stroke incidence and stroke mortality in 20 years of follow-up in men and women in the Renfrew/Paisley study in Scotland. Stroke 2000;31:1893-6.

15 Cox DR. Regression models and life tables. Journal of the Royal Statistical Society (B) 1972;34:187-220.

16 Moyes CD. Stature and birth rank. A study of schoolchildren in St Helena. Arch Dis Child 1981;56:116-20.

17 O'Leary SR, Wingard DL, Edelstein SL, et al. Is birth order associated with adult mortality? Ann Epidemiol 1996;6:34-40.

18 Lundberg 0 . The impact of childhood living conditions on illness and mortality in adulthood. Soc Sci Med 1993;36:1047-52.

19 Wagner ME, Schubert HJ, Schubert DS. Family size effects: a review. J Genet Psychol 1985;146:65-78.

20 Whincup P, Cook D, Papacosta $O$, et al. Relation of blood pressure to number of siblings. N Engl J Med 1991;325:891.

21 Okasha M, McCarron P, McEwen J, et al. Determinants of adolescent blood pressure: findings from the Glasgow University student cohort. J Hum Hypertens 2000; 14:117-24.

22 Trevisan M, Krogh V, Klimowski L, et al. Absence of siblings-a risk factor for hypertension? N Engl J Med 1991;324:1285-5.

23 Ravelli G, Belmont L. Obesity in nineteen-year-old men: family size and birth order associations. Am J Epidemiol 1979;109:66-70.

24 Scott JA. Intelligence, physique, and family size. Br J Prev Soc Med 1962;16:165-73.

25 Grant MW. Rate of growth in relation to birth rank and family size. Br J Prev Soc Med 1964;18:35-42.

26 Rona R, Chinn S. Genetic and environmental influences on growth. J Med Screen 1995;2:133-9.

27 McGonigle G, McKinlay P. An investigation into the effect of certain factors upon child health and child weight. Journal of Hygiene 1932;XXXII:465-88

28 Szklo M, Tonascia J, Gordis L. Psychosocial factors and the risk of myocardial infarctions in white women. Am J Epidemio 1976:103:312-20.

29 Paffenbarger Jr R, Wolf $\mathrm{P}$, Notkin J, et al. Chronic disease in former college students. 1. Early precursors of fatal coronary heart disease. Am J Epidemiol 1966:83:314-28.

30 Rose G. Familial patterns in ischaemic heart disease. Br J Prev Soc Med 1964;18:75-0

31 Oscherwitz M, Krasnoff S, Moretti L, et al. The relationship of myocardial infarction to parental mortality and longevity. J Chron Dis 1968;21:341-8.

32 Vitullo F, Marchioli R, Di Mascio R, et al. Family history and socioeconomic factors as predictors of myocardial infarction, unstable angina and stroke in an Italian population. Eur J Epidemiol 1996; 12:177-85

33 Ball T, Castro-Rodriguez J, Griffith K, et al. Siblings, day-care attendance, and the risk of asthma and wheezing during childhood. $N$ Engl J Med 2000;343:538-43.

34 Helicobacter and Cancer Collaborative Group. Gastric cancer and Helicobacter pylori: a combined analysis of 12 case control studies nested within prospective cohorts. Gut 2001;49:347-53.

35 Parsonnet J. Helicobacter pylori and gastric adenocarcinoma. In: Parsonnet J, ed. Microbes and malignancy. Infection as a cause of human cancers. New York: Oxford University Press, 1999:372-408.

36 Woodward M, Morrison C, McColl K. An investigation into factors associated with Helicobacter pylori infection. J Clin Epidemiol 2000;53:175-81

37 Hansson L, Baron J, Nyren O, et al. Early-life risk indicators of gastric cancer. A population-based case-control study in Sweden. Int J Cancer 1994;57:32-7.

38 Hemminki K, Mutanen P. Birth order, family size, and the risk of cance in young and middle-aged adults. Br J Cancer 2001;84:1466-71.

39 McCarron P, Hart CL, Hole DJ, et al. The relation between adult height and haemorrhagic and ischaemic stroke in the Renfrew/Paisley study. $J$ Epidemiol Community Health $2001 ; 55: 404-5$

40 Eriksson JG, Forsen T, Tuomilehto J, et al. Early growth, adult income, and risk of stroke. Stroke 2000;31:869-74.

41 Hypponen E, Leon D, Kenward M, et al. Prenatal growth and risk of occlusive and haemorrhagic stroke in Swedish men and women born 1915-29: historical cohort study. BM 2001;323:1033-4.

42 Kramer MS. Determinants of low birth weight: methodological assessment and meta-analysis. Bull World Health Organ 1987;65:663-737.

43 Yates P. A change in the pattern of cerebrovascular disease. Lancet 1964;i:65-9.

44 Leon DA, Davey Smith G. Infant mortality, stomach cancer, stroke, and coronary heart disease: ecological analysis. BM 2000;320:1705-6.

45 Danesh J, Appleby P. Persistent infection and vascular disease: a systematic review. Exp Opin Invest Drugs 1998;7:691-713. 